\title{
MASS APPRAISAL OF RESIDENTIAL REAL ESTATE USING MULTILEVEL MODELLING
}

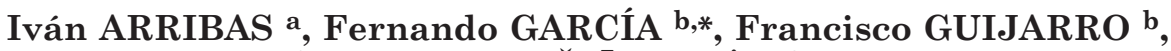 \\ Javier OLIVER ${ }^{b}$, Rima TAMOŠIŪNIENE \\ a Department of Economic Analysis, Universitat de València, ERI-CES and Ivie, Av. dels Tarongers \\ $s / n, 46022$ Valencia, Spain \\ ${ }^{b}$ Department of Economics and Social Sciences, Universitat Politècnica de València, Camí de Vera s/n, \\ 46022 Valencia, Spain \\ ${ }^{c}$ Department of Finance Engineering, Vilnius Gediminas Technical University, Sauletekio al. 11, LT- \\ 10223 Vilnius, Lithuania \\ ${ }^{d}$ Institute of Economics and Business, Faculty of Economics and Finance Management, Mykolas Rom- \\ eris University, Ateities g. 20 LT-08303 Vilnius, Lithuania
}

Received 16 October 2015; accepted 15 December 2015

\begin{abstract}
Mass appraisal, or the automatic valuation of a large number of real estate assets, has attracted the attention of many researchers, who have mainly approached this issue employing traditional econometric models such as Ordinary Least Squares (OLS). However, this method does not consider the hierarchical structure of the data and therefore assumes the unrealistic hypothesis of the independence of the individuals in the sample. This paper proposes the use of the Hierarchical Linear Model (HLM) to overcome this limitation. The HLM also gives valuable information on the percentage of the variance error caused by each level in the hierarchical model. In this study HLM was applied to a large dataset of 2,149 apartments, which included 17 variables belonging to two hierarchical levels: apartment and neighbourhood. The model obtained high goodness of fit and all the estimated variances of the parameters in HLM were lower than those calculated by OLS. It can be concluded as well that no further neighbourhood variables need be added to the model to improve the goodness of fit, since almost all the residual variance can be attributed to the first hierarchical level of the model, the apartment level.
\end{abstract}

KEYWORDS: Housing market; Price modelling; Mass appraisal; Hierarchical linear model; Real estate

\section{INTRODUCTION}

The real estate market plays an important role in the economy, influencing aspects such as public policies, taxation, financial system stability, employment, household spending, etc., as the recent economic crisis has clearly revealed. For this reason, it is not surprising that this market has been carefully studied from different perspectives, especially in recent time, focusing on topics like price formation (Aznar et al. 2010), investment decisions (Cervelló et al. 2011), taxation (Raslanas et al. 2010) or life quality (Štreimikienè 2014), just to mention some examples. Another important and recurrent research topic is residential real estate mass appraisal.

\footnotetext{
* Corresponding author. E-mail: fergarga@esp.upv.es
}

Mass appraisal is the systematic appraisal of groups of properties as of a given date using standardized procedures and statistical testing (Gloudemans 1999). In the case of residential real estate valuations, there are different public and private organizations that benefit from mass appraisal for different ends, e.g. local governments employ such valuations to calculate certain taxes, banks use it to value real estate assets offered as mortgage collateral, investment funds to estimate the price of real estate portfolios, and valuation companies use it to monitor the valuations calculated by their staff, etc.

The usefulness of mass appraisal has triggered the proposal and application of different methodologies, which can be classified into two groups: one 
based on an econometric approach and another based on the artificial intelligence approach. The former includes regression models and their multiple variants. The second group is well represented in the literature and includes approaches like decision trees (Fan et al. 2006), rough set theory (D'Amato 2007), artificial neural networks (Tay, Ho 1992; García et al. 2008; Selim 2009), support vector machines (Kontrimas, Verikas 2011) and random forest (Antipov, Pokryshevskaya 2012).

It is common that real estate appraisers incorporate in their valuation activity methodologies that have already been tested in other fields and are frequently used for other purposes. So, for example, habitual and well-established methodologies like DEA (Titko et al. 2014), AHP (Ecer 2014) or econometric models (Mihi-Ramirez et al. 2013; Rudzkis, Valkavičienè 2014) have been introduced into the appraisers' practice as well (D'Amato 2010; Aznar et al. 2011; Narula et al. 2012; Cervelló et al. 2011).

In this paper we propose to apply an econometric model, the hierarchical linear model (hereafter HLM) to mass valuation. HLM are also known as multilevel models, mixed models, random effect models or variance components models. This method has already been used in other fields but, to the authors' knowledge, has so far not been applied to mass valuation. Hierarchical linear models have been successfully used since the $80 \mathrm{~s}$ in the fields of education (Aitkin et al. 1981; Raudenbush, Bryck 1986; Singh 2014), public policy (Duncan et al. 1993; Tso, Guan 2014), criminology (Gelman 2007; Fagan et al. 2015), and politics (Wang et al. 2015). This method overcomes some limitations of the traditional regression models, which are based on the hypothesis that the individuals in the sample are independent, however this assumption is not always correct. HLM also provides valuable information on the percentage of the variance error caused by each level in the hierarchical model. In this paper, the variables are grouped into two hierarchical levels (those which describe the apartment and those which describe the neighbourhood) in order to determine which group of variables best explains price variability.

Another important contribution of the present research is the use of a large database with a great number of observations and explanatory variables, which makes the results obtained more robust than those of previous studies in which the database was more limited in terms of observations and explanatory variables.
The remainder of the paper is structured as follows. The next section presents a brief review of the literature on the use of econometric models for mass appraisal of residential real estate. Section 3 introduces the proposed method, i.e. the Hierarchical Linear Model. Section 4 describes the database employed to estimate the econometric models. Section 5 presents the application of HLM to the mass valuation of apartments in the city of Alicante, Spain, and Section 6 contains our conclusions.

\section{THE USE OF ECONOMETRIC MODELS FOR MASS APPRAISAL OF RESIDENTIAL REAL ESTATE}

Econometric models, or more specifically, hedonic regression models, have been extensively applied in the literature and are widely used by both academics and practitioners in residential real estate mass appraisal. A large number of academic studies have employed regression models for real estate valuation from the decade of the 80 s to the present. These studies apply different econometric models with different complexity levels, like the traditional hedonic regression models (Palmquist 1984; Isakson 2001; Downes, Zabel 2002), ridge regression (Ferreira, Sirmans 1988) or quantile regression (Farmer, Lipscomb 2010; Narula et al. 2012), just to mention some examples.

Hedonic price models are employed to assess the factors that affect house prices, including the characteristics of both the house and its neighbourhood. However, in the traditional model these factors are regarded as independent and are not interrelated in the analysis, which means that the influence of the house characteristics on the price is considered to be constant, regardless of its location. This assumption cannot correctly reflect the real situation, as the characteristics of a neighbourhood are not independent of those of the house and the two may interfere with each other. According to Basu and Thibodeau (1998), when spatial autocorrelation exists in the error term in a hedonic price equation, the assessment results of the parameters may be subject to error. Incorrect coefficients may also be caused by the explanatory variables in the model, leading to wrong conclusions.

This is because the traditional regression models do not consider the multilevel or hierarchical structure that generates house prices. Houses are located within neighbourhoods and neighbourhoods within cities, so this hierarchy must be employed to reflect the spatial heterogeneity of house prices. 
Brown and Uyar (2004) consider that HLM can be applied to overcome these problems and correctly assess the implicit price of a house with non-constant variance and spatial heterogeneity. In other words, HLM can be used to separate the variation in housing prices into a portion that depends on house-specific characteristics and another portion that depends on neighbourhood-specific characteristics. These authors also note that although GIS data can be used for neighbourhood effects and spatial correlation, it will not identify the impact of individual neighbourhood characteristics on the price of a house.

Although the application of the HLM is promising, its use in real estate valuation has been limited. Lee (2009) explored the influence of satisfaction with public facilities on housing prices; Giuliano et al. (2010) analyzed the relationship between accessibility and residential land value. In a pioneer study by Brown and Uyar (2004) a HLM approach was introduced to assess the effects of house and neighbourhood characteristics on housing prices, but only the area was used to describe the dwellings. As far as we know, HLM has not yet been employed on mass appraisal, which is characterized by the intensive use of standardized procedures on a large database, including a high number of observations and explanatory variables of the price.

\section{METHODOLOGY}

Our analysis applies HLM, as the database is hierarchically structured with apartments (Level 1 units) clustered within postal codes (Level 2 units).

Postal codes are used as a proxy for the different neighbourhoods in a city. HLM models are statistically more efficient than analyses that only consider the apartment level, those that only consider the postal code level, or those that use both with data panel techniques. As mentioned above, considering the clustered nature of the database allows unbiased effects and robust standard errors to be estimated and correct significance tests to be produced. HLM also allows for the inclusion of both variables at apartment level (e.g. number of rooms) and postal code level (e.g. commercial characteristics of the neighbourhood).

HLM was fitted to the data using the lme4 package in R statistical software (R Core Team 2014). Different models were fitted for different levels for explanatory variables. The output of these analyses has two parts: fixed effects for each explanatory variable that are interpreted in the ordinary multiple regression sense (the average effect of the explanatory variable on the response variable); and random effects that describe the unexplained variability in the response variable. There are two random parameters, one for the Level 1 (apartment) variation and one for the Level 2 (postal code) variation. This comparison makes it possible to estimate the percentage of variation attributable to Level 2 (variance partition coefficient).

The statistical significance of any of the estimated parameters is tested by comparing the goodness of fit of two alternative models and testing whether the improvement in fit is statistically significant.

\subsection{Model formulation}

The literature on residential real estate valuations has considered a variety of alternative models in which the set of explanatory variables depends partially on the information available: size of the apartment, number and type of rooms, year of construction, characteristics of the block and the floor on which the apartment is located, among others. The most frequently used dependent variables are apartment price and price per square meter. Given the hierarchical nature of the data in which apartments are nested within geographical areas (postal codes), fixed effects are also included to capture between-postal code differences in price levels.

Thus, we can write the general model to be estimated as:

$$
\begin{aligned}
& Y_{i j}=\beta_{0}+\sum_{k} \beta_{k} x_{i j k}+\sum_{j} \beta_{j} G_{j}+\varepsilon_{i j}, \\
& i=1, \ldots, I ; j=1, \ldots, J
\end{aligned}
$$

where: $Y_{i j}$ represents the price for apartment $i$ in postal code $j ; x_{i j k}$ represents the $k$ explanatory variable, and $G$ is the vector of geographical fixed effects. The parameters to be estimated are $\beta_{k}$ and $\beta_{j}$, and $\varepsilon_{i j}$ is the error term.

Model 1 can be estimated by ordinary least squares (OLS), assuming that the apartments under study are independent. More specifically, OLS assumes that the residuals $\varepsilon_{i j}$ are uncorrelated, $\operatorname{Var}(\varepsilon)=\sigma^{2} I$. However, in grouped data the group effect must be considered, which means that the independence assumption will not hold. One effect of ignoring clustering is that the standard errors of the OLS parameters will be incorrectly estimated and no inference can be properly applied.

HLM can estimate the correct standard errors and analyse the nature of between-group variability and the effect of a grouping-level characteristic on an individual outcome, identify outlying groups and estimate group effects simultaneously with the effects of group-level explanatory variables. 


\subsection{Multilevel model formulation}

In the simplest HLM formulation we consider the one-level random-intercept Model 2:

$$
Y_{i j}=\beta_{0}+\sum_{k} \beta_{k} x_{i j k}+\sum_{k} \beta_{k} G_{j k}+u_{j}+\varepsilon_{i j},
$$

where: $u_{j}$ is the group random effect (group-level residual) for group $j$. Thus, the overall conditioned mean is $\beta_{0}+\sum_{k} \beta_{k} x_{i j k}$, but the conditioned mean for the group $j$ is $\beta_{0}+\sum_{k} \beta_{k} x_{i j k}+u_{j}$, so that $u_{j}$ can be understood as the difference of group j's mean and the overall mean.

The basic assumptions on the group-level residuals are that they are independent and normally distributed with zero mean, $u \sim N\left(0, \sigma_{u}^{2} I\right)$; the individual-level residuals verify the same assumptions $\varepsilon \sim N\left(0, \sigma_{\varepsilon}^{2} I\right)$; and group-level residuals are uncorrelated with individual-level residuals, thus total variance for individual $i j$ is $\sigma_{u}^{2}+\sigma_{\varepsilon}^{2}$. The proportion of total variance explained by differences between groups is called the variance partition coefficient $V P C=\sigma_{u}^{2} /\left(\sigma_{u}^{2}+\sigma_{\varepsilon}^{2}\right)$.

\section{DATABASE}

Together with the application of HLM to mass valuation, the other novel feature of the present study is the large database employed, which consists of information on 2,149 apartments in the city of Alicante, Spain. 17 variables were collected for each apartment: 6 describe its characteristics, 7 describe the building in which it is sited and 4 describe the neighbourhood.

This large database contrasts with those used in most of the studies in this field, regardless of the valuation method applied, e.g. Brown and Uyar (2004) considered data for 725 dwellings and only one explanatory variable; d'Amato (2007) worked with 390 observations; García et al. (2008) used 591 sample cases; in Kontrimas and Verikas (2011) the sample size was 100; and Narula et al. (2012) considered 54 observations.

In the present study each apartment is described by the following variables:

A. Apartment characteristics:

a.1. Price: apartment price in euros;

a.2. Area: total area of the apartment in square meters;

a.3. Terrace: binary variable indicating whether or not the apartment has a terrace;

a.4. Floor: floor on which the apartment is located;

a.5. Bedrooms: number of bedrooms;

a.6. Bathrooms: number of bathrooms.
B. Block characteristics, which include both quantitative and qualitative variables:

b.1. Number of apart.: number of apartments in the block;

b.2. Lifts: binary variable indicating whether or not the block has a lift;

b.3. Number of floors: number of floors in the block;

b.4. Age of block: age of the block in years;

b.5. Location: indicates the position of the block as a qualitative variable in four levels. "Very good" means that the building is near the sea front or an important facility. "Good" is assigned when it is in a boulevard or large square. "Fair" is for an average street or thoroughfare and "Bad" means it is in a narrow street or poor neighbourhood;

b.6. Quality: describes the quality of the block construction as a qualitative variable. Two levels are considered: "High" and "Medium";

b.7. Community spaces: this qualitative variable indicates the existence of community spaces. Buildings are clustered into two groups: "None" (no community spaces) or "With community spaces";

C. Neighbourhood characteristics, which only include qualitative variables:

c.1. Commerce: commercial activity. Can be described as "Bad", "Fair", "Good" or "Very good";

c.2. Neighbourhood: general perception of the neighbourhood. Can be "Very bad", "Bad", "Fair", "Good" or "Very good";

c.3. Income: perception of the neighbourhood residents' income group classified into "High", "Medium-High", "Medium", "Medium-Low" and "Low";

c.4. Density: density of the neighbourhood population levels is "High" and "Medium".

All these variables are grouped into the two hierarchical levels defined in our HLM model. Apartment characteristics and block characteristics are assigned to Level 1 (apartment/block level), whereas neighbourhood characteristics are assigned to Level 2 (postal code/neighbourhood level).

We recoded any variable that had either almost empty levels or too many levels, to reduce its number of levels and thus significantly reduce the number of parameters to be estimated in OLS and HLM. There are no missing values in the database because real estate appraisers need all this information to assess the property.

Descriptive statistics for both quantitative and qualitative variables are given in Tables $1-3$. The representative apartment (single-family residential property) has 100 square meters, no terrace, 3 bedrooms, 2 bathrooms and is worth $€ 165,000$ (median value). 
Table 1. Descriptive statistics for quantitative variables

\begin{tabular}{|c|c|c|c|c|c|c|c|}
\hline Apartment & $\mathrm{N}$ & Mean & Median & Minimum & Maximum & Std._deviation & Coef._var. \\
\hline Price & 2,149 & $196,069.08$ & $165,000.00$ & $27,550.00$ & $1,745,000.00$ & $151,180.36$ & 0.77 \\
\hline Area & 2,149 & 103.24 & 100.00 & 25.00 & 300.00 & 33.13 & 0.32 \\
\hline Terrace $(*)$ & 2,149 & 0.13 & 0.00 & 0.00 & 1.00 & 0.34 & 2.59 \\
\hline Floor & 2,149 & 4.35 & 4.00 & 1.00 & 24.00 & 2.42 & 0.56 \\
\hline Bedrooms & 2,149 & 2.95 & 3.00 & 1.00 & 6.00 & 0.86 & 0.29 \\
\hline Bathrooms & 2,149 & 1.60 & 2.00 & 1.00 & 5.00 & 0.55 & 0.35 \\
\hline Block & $\mathrm{N}$ & Mean & Median & Minimum & Maximum & Std._deviation & Coef._var. \\
\hline $\begin{array}{l}\text { Number of } \\
\text { apart. }\end{array}$ & 2,149 & 19.72 & 15.00 & 1.00 & 496.00 & 29.81 & 1.51 \\
\hline Lifts $\left(^{*}\right)$ & 2,149 & 0.70 & 1.00 & 0.00 & 1.00 & 0.46 & 0.65 \\
\hline $\begin{array}{l}\text { Number of } \\
\text { floors }\end{array}$ & 2,149 & 6.82 & 6.00 & 2.00 & 35.00 & 3.24 & 0.48 \\
\hline Age of block & 2,149 & 18.68 & 25.00 & 0.00 & 40.00 & 11.74 & 0.63 \\
\hline
\end{tabular}

(*) 1 = Yes; 0 = No.

Price is extremely skewed to the right, as shown by the difference between the average and the median jointly with the coefficient of variation (0.77). We partially solve this problem considering the log of price. Following most previous studies, we also considered the log transformation for several variables: Area, Floor, Bedrooms, Bathrooms, and Number of apartments.

The typical block has 15 apartments, a lift, 6 floors, is 25 years old, has no community spaces, construction quality is "Medium" and its location is defined as "Fair" (Table 2).

Most apartments are in a "Good" neighbourhood, with "Medium" income, "Good" commercial services and "High" density (Table 3).

The lowest level of the qualitative variables that describe the neighbourhood was chosen as the reference level in the analysis. For example, the reference level for the commercial services in the regressions is Fair/Bad to simplify the interpretation of the coefficient signs in the regression models.

Table 2. Description of the real estate qualitative variables

\begin{tabular}{lll}
\hline Variables & $\mathrm{N}$ & $\%$ \\
\hline Location & & \\
$\quad$ Very good & 88 & 4.09 \\
Good & 467 & 21.73 \\
Fair & 1,578 & 73.43 \\
Bad & 16 & 0.74 \\
Quality & & \\
$\quad$ High & 57 & 2.65 \\
$\quad$ Medium & 2,092 & 97.35 \\
Community spaces & & \\
$\quad$ None & 1,700 & 79.11 \\
$\quad$ With community spaces & 449 & 20.89 \\
\hline
\end{tabular}

The hierarchical analysis is applied on two levels; the first examines the influence of building characteristics (apartment and block) on price, while the second level measures the influence of the neighbourhood. In order to undertake this two-level-analysis, information must be available in the database about the apartments' postal code, as in our case, which can thus be used as a proxy for the neighbourhood.

Our initial hypothesis is that there is greater homogeneity among apartments belonging to the same postal code and greater heterogeneity among apartments in different postal codes.

Table 3. Description of the neighbourhood qualitative variables

\begin{tabular}{|c|c|c|}
\hline Variables & $\mathrm{N}$ & $\%$ \\
\hline \multicolumn{3}{|l|}{ Commerce } \\
\hline Fair/Bad & 175 & 8.14 \\
\hline Good & 1,566 & 72.87 \\
\hline Very good & 408 & 18.99 \\
\hline \multicolumn{3}{|l|}{ Neighborhood } \\
\hline Very bad & 38 & 1.77 \\
\hline Fair & 155 & 7.21 \\
\hline Good & 1,420 & 66.08 \\
\hline Very good & 536 & 24.94 \\
\hline \multicolumn{3}{|l|}{ Income } \\
\hline High & 361 & 16.80 \\
\hline Medium-High & 452 & 21.03 \\
\hline Medium & 1,189 & 55.33 \\
\hline Medium-Low & 107 & 4.98 \\
\hline Low & 40 & 1.86 \\
\hline \multicolumn{3}{|l|}{ Density } \\
\hline High & 2,047 & 95.25 \\
\hline Medium & 102 & 4.75 \\
\hline
\end{tabular}




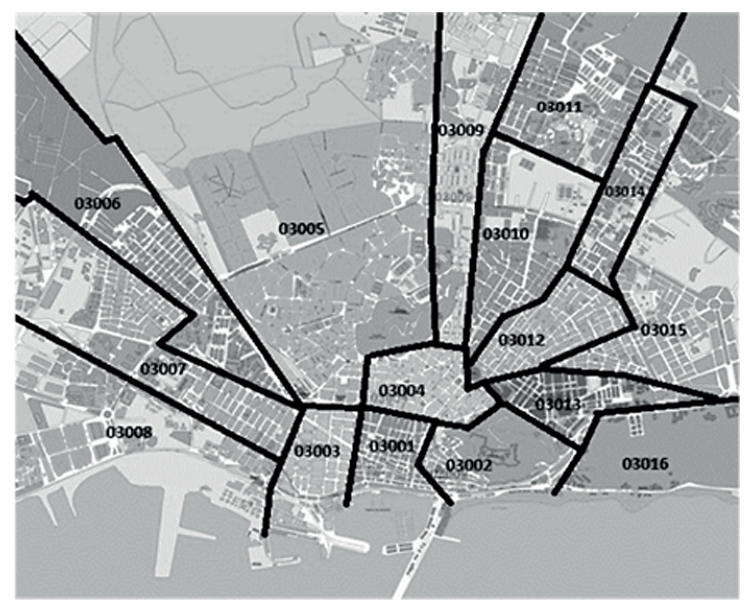

Fig. 1. Map of the city of Alicante with postal codes

Figure 1 shows a map of the city of Alicante and the distribution of its 16 postal codes. The location of the postal codes provides information on the city's urban development. Postal codes 03000 to 03004 are in Alicante's historic city center, front onto the sea and are very attractive from the tourist and commercial point of view. They have good facilities and services, are well connected, and many of the city's best-known buildings are located there.

In the 20th century Alicante experienced significant demographic growth which triggered a major geographical expansion and the city has continued growing as a consequence of the real estate bubble at the beginning of the 21st century. As a result of these expansion periods, new neighbourhoods with different characteristics have been created over the years and Alicante has become an important tourist resort. In this context, special attention must be given to postal code 03016, which fronts onto the sea, as the demand from tourists in this area may influence the behaviour of real estate prices.

Postal code 03005 contains the largest number of apartments in our sample (249 apartments or $11.5 \%$ of the sample) and 0314 has the smallest (61 apartments, $2.8 \%$ of the sample).

\section{EMPIRICAL ANALYSIS}

This section discusses the results obtained from applying HLM and compares the results with those from OLS.

Our analysis considers four model specifications (Table 4). Models 1 to 3 are fitted only by HLM. Model 4a is fitted by HLM and Model 4b is fitted by the OLS approach for purposes of comparison. All HLM models are estimated with random intercept. The OLS model includes fixed effects for each postal code.
The specification of Model 1 only includes the intercept, with no explanatory variables for price. This is the base model and will be used to calculate the pseudo- $\mathrm{R}^{2}$ (Snijders, Bosker 1999; Giuliano et al. 2010). Model 2 includes the apartment characteristics as explanatory variables and Model 3 incorporates block characteristics. Both versions of Model 4 use all apartment, block and neighbourhood variables.

The comparison of the four HLM models is done by determining the significant variables and whether there are changes regarding the magnitude of the coefficients. Pseudo- $\mathrm{R}^{2}$ is also compared, as is the reduction in total variance explained by inter-group differences, or the so called variance partition coefficient.

For Model 4, HLM and OLS are compared using the estimated fixed effects and their standard error, as well as the criteria commonly employed to measure goodness of fit: mean absolute percentage error (MAPE), mean absolute error (MAE), and root of the mean square error (RMSE).

The results given in Table 4 show that all apartment variables are highly significant, regardless of the regression model estimated. As pointed out in Tanaka et al. (1982), the fact that the bedroom coefficient is negative is due to the strong correlation between this variable and Area. In the case of fixed floor space, the larger the number of rooms, the lower the price, since smaller rooms reduce prices.

When considering block variables (Model 3), some variables included in Model 2 drastically reduce their coefficient in absolute terms, especially the Floor coefficient, which goes from 0.083 to 0.046. The Bedrooms coefficient drops from -1.559 to -0.697 and the Bathrooms coefficient is reduced from 0.312 to 0.079 .

Most of the variables that describe block characteristics show highly significant results, in both in Models 3 and 4, with both HLM and OLS: Number of apartments, Age of block, Lift, Quality and "Very Good" for Location. The remaining Location options and Community spaces are not significant.

The coefficient signs are as expected. In this case, the coefficients of the variables Number of apartments and Age of block have a negative sign, showing that the more the apartments in a building and the older the block, the lower the price and that both "High" quality and "Very good" location blocks are worth higher prices. When the variables describing the neighbourhood are included in Model 4, the coefficient of "Very Good" for Location is reduced, since some neighbourhood characteristics are related to block features. 
Table 4. Model estimation and goodness of fit

\begin{tabular}{|c|c|c|c|c|c|}
\hline & HLM Model 1 & HLM Model 2 & HLM Model 3 & $\begin{array}{l}\text { HLM Model } \\
4 . \mathrm{a}\end{array}$ & $\begin{array}{l}\text { OLS Model } \\
4 . \mathrm{b}\end{array}$ \\
\hline (Intercept) & $\begin{array}{l}11.974 * * * \\
(0.101)\end{array}$ & $\begin{array}{l}9.365 * * * \\
(0.231)\end{array}$ & $\begin{array}{l}9.154 * * * \\
(0.202)\end{array}$ & $\begin{array}{l}8.912 * * * \\
(0.179)\end{array}$ & $\begin{array}{l}9.016 * * * \\
(0.181)\end{array}$ \\
\hline $\log$ (Area) & & $\begin{array}{l}0.561 * * * \\
(0.053)\end{array}$ & $\begin{array}{l}0.587 * * * \\
(0.044)\end{array}$ & $\begin{array}{l}0.572 * * * \\
(0.040)\end{array}$ & $\begin{array}{l}0.573 * * * \\
(0.040)\end{array}$ \\
\hline $\log$ (Floor) & & $\begin{array}{l}0.083 * * * \\
(0.011)\end{array}$ & $\begin{array}{l}0.046 * * * \\
(0.010)\end{array}$ & $\begin{array}{l}0.044 * * * \\
(0.009)\end{array}$ & $\begin{array}{l}0.044 * * * \\
(0.009)\end{array}$ \\
\hline $\log ($ Bedrooms $)$ & & $\begin{array}{l}-1.559 * * * \\
(0.179)\end{array}$ & $\begin{array}{l}-0.697 * * * \\
(0.150)\end{array}$ & $\begin{array}{l}-0.606 * * * \\
(0.136)\end{array}$ & $\begin{array}{l}-0.576 * * * \\
(0.137)\end{array}$ \\
\hline $\log ($ Bathrooms) & & $\begin{array}{l}0.312 * * * \\
(0.023)\end{array}$ & $\begin{array}{l}0.079 * * * \\
(0.022)\end{array}$ & $\begin{array}{l}0.054 * * \\
(0.020)\end{array}$ & $\begin{array}{l}0.052 * * \\
(0.020)\end{array}$ \\
\hline Terrace: Yes versus No & & $\begin{array}{l}0.117 * * * \\
(0.017)\end{array}$ & $\begin{array}{l}0.111 * * * \\
(0.014)\end{array}$ & $\begin{array}{l}0.099 * * * \\
(0.013)\end{array}$ & $\begin{array}{l}0.099 * * * \\
(0.013)\end{array}$ \\
\hline $\log ($ Area $) * \log ($ Bedrooms $)$ & & $\begin{array}{l}0.295 * * * \\
(0.040)\end{array}$ & $\begin{array}{l}0.147 * * * \\
(0.034)\end{array}$ & $\begin{array}{l}0.130 * * * \\
(0.031)\end{array}$ & $\begin{array}{l}0.125 * * * \\
(0.031)\end{array}$ \\
\hline $\log$ (Number of apartments) & & & $\begin{array}{l}-0.027 * * \\
(0.009)\end{array}$ & $\begin{array}{l}-0.031 * * * \\
(0.008)\end{array}$ & $\begin{array}{l}-0.030 * * * \\
(0.008)\end{array}$ \\
\hline Age of block & & & $\begin{array}{l}-0.006 * * * \\
(0.001)\end{array}$ & $\begin{array}{l}-0.006 * * * \\
(0.001)\end{array}$ & $\begin{array}{l}-0.006 * * * \\
(0.001)\end{array}$ \\
\hline Lift: Yes versus No & & & $\begin{array}{l}0.192 * * * \\
(0.016)\end{array}$ & $\begin{array}{l}0.166 * * * \\
(0.015)\end{array}$ & $\begin{array}{l}0.163 * * * \\
(0.015)\end{array}$ \\
\hline Location: Fair versus Bad & & & $\begin{array}{l}0.051 \\
(0.057)\end{array}$ & $\begin{array}{l}-0.075 \\
(0.053)\end{array}$ & $\begin{array}{l}-0.068 \\
(0.053)\end{array}$ \\
\hline Location: Good versus Bad & & & $\begin{array}{l}0.193 * * \\
(0.059)\end{array}$ & $\begin{array}{l}0.018 \\
(0.055)\end{array}$ & $\begin{array}{l}0.026 \\
(0.056)\end{array}$ \\
\hline Location: Very good versus & & & $0.573 * * *$ & $0.396 * * *$ & $0.402 * * *$ \\
\hline $\mathrm{Bad}$ & & & $(0.063)$ & $(0.059)$ & $(0.060)$ \\
\hline Quality: High versus Medium & & & $\begin{array}{l}0.309 * * * \\
(0.033)\end{array}$ & $\begin{array}{l}0.275 * * * \\
(0.030)\end{array}$ & $\begin{array}{l}0.274 * * * \\
(0.030)\end{array}$ \\
\hline Community spaces: With & & & -0.030 & -0.002 & -0.001 \\
\hline Commerce: Good versus & & & $(0.019)$ & -0.008 & -0.023 \\
\hline Fair/Bad & & & & $(0.041)$ & $(0.042)$ \\
\hline Commerce: Very good versus & & & & $0.171 * * *$ & $0.151 * *$ \\
\hline Fair/Bad & & & & $(0.048)$ & $(0.049)$ \\
\hline Income: Medium-Low versus & & & & 0.098 & 0.090 \\
\hline Low & & & & $(0.143)$ & $(0.144)$ \\
\hline Income: Medium versus Low & & & & $\begin{array}{l}0.260 \\
(0.146)\end{array}$ & $\begin{array}{l}0.252 \\
(0.147)\end{array}$ \\
\hline Income: Medium-High versus & & & & $0.382 * *$ & 0.364 * \\
\hline Low & & & & $(0.147)$ & $(0.148)$ \\
\hline Income: High versus Low & & & & $\begin{array}{l}0.477 * * \\
(0.149)\end{array}$ & $\begin{array}{l}0.453 * * \\
(0.150)\end{array}$ \\
\hline Density: High versus Medium & & & & $\begin{array}{l}0.049 * \\
(0.024)\end{array}$ & $\begin{array}{l}0.051 * \\
(0.024)\end{array}$ \\
\hline Neighborhood: Fair versus & & & & -0.075 & -0.082 \\
\hline Very bad & & & & $(0.145)$ & $(0.146)$ \\
\hline Neighborhood: Good versus & & & & 0.100 & 0.085 \\
\hline Very bad & & & & $(0.149)$ & $(0.150)$ \\
\hline $\begin{array}{l}\text { Neighborhood: Very good } \\
\text { versus Very bad }\end{array}$ & & & & $\begin{array}{l}0.178 \\
(0.150)\end{array}$ & $\begin{array}{l}0.153 \\
(0.151)\end{array}$ \\
\hline Random effects: & & & & & \\
\hline Total variance & 0.319 & 0.139 & 0.102 & 0.042 & 0.039 \\
\hline Neighborhood variance & 0.163 & 0.068 & 0.054 & 0.003 & - \\
\hline Residual variance & 0.156 & 0.071 & 0.048 & 0.039 & 0.039 \\
\hline $\begin{array}{l}\text { Variance Partition Coefficient } \\
\text { Goodness of fit: }\end{array}$ & 51.177 & 49.110 & 53.194 & 7.856 & \\
\hline Pseudo $\mathrm{R}^{2}$ ( $\mathrm{R}^{2}$ for OLS Model 4.b) & & 0.563 & 0.681 & 0.867 & 0.863 \\
\hline MAE & $63,080.412$ & $43,746.889$ & $34,839.939$ & $31,430.820$ & $31,457.258$ \\
\hline MAPE & 30.345 & 20.324 & 16.976 & 15.281 & 15.273 \\
\hline RMSE & $131,483.266$ & $92,758.127$ & $64,488.038$ & $59,213.925$ & $59,308.286$ \\
\hline Num. obs. & 2,149 & 2,149 & 2,149 & 2,149 & 2,149 \\
\hline Num. groups: PC & 16 & 16 & 16 & 16 & 16 \\
\hline
\end{tabular}

$* * * p<0.001,{ }^{* *} p<0.01,{ }^{*} p<0.05$. 
Model 4 includes Level 2 variables. Here again, those characteristics that are significant when applying HLM are also significant with OLS. The significant neighbourhood variables at a significance level of 5\% or lower are: "Very Good" for Commercial Services, and "Low", "High" and "MediumHigh" for Income. The remainder of the neighbourhood variables is not significant.

As for the magnitude of the coefficients, no important differences are observed other than those already mentioned. The positive or negative sign is identical for all models. It is worth mentioning that the variance of the coefficients is always smaller in HLM than in OLS. However, the observations are not independent, so that OLS estimations are inefficient and lead to higher variances than those in HLM.

The different models we developed make it possible to analyse the evolution of total variance and the variance partition coefficient. In this way we can calculate the percentage of the total variance explained by differences in neighbourhoods/postal codes (group-level) and by differences at the apartment/block level (individual-level). This analysis is not possible when OLS is employed, as in this case only the variance of the individual-level residuals can be calculated.

Table 4 also shows variance components: neighbourhood variance, which is the group-level variance generated by differences between neighbourhoods not captured in the model; and residual variance, which is the individual-level variance generated by differences between the apartments that are also not captured in the model.

In Model 2 the neighbourhood effect is not captured, as this model only includes apartment variables, so that neighbourhood variance is responsible for as much as $49.1 \%$ of the total variance.

When block characteristics are included in Model 3, the neighbourhood variance drops by $20 \%$ with respect to Model 2 (from 0.068 to 0.054 ). The reduction observed in the residual variance is larger, $32 \%$, from 0.071 to 0.048 . The reason for this is that Model 3 includes more important variables at the individual level, so that although total variance is reduced, the percentage of this variance at group level increases to $53.2 \%$.

When neighbourhood descriptive variables are introduced in Model 4a, the total variance experiences a drastic reduction, from 0.102 in Model 3 to just 0.042 in Model 4a. This reduction is larger than the one obtained with block variables, since in that case total variance shifted from 0.139 in Model 2 to 0.102 in Model 3. Since both Models
2 and 3 only cover individual-level variables, it seems reasonable that introducing variables at a new level has a big impact on the accuracy of the model. Looking closer at the variance components, we notice that neighbourhood variance is reduced by $94 \%$ (from 0.054 in Model 3 to just 0.003 in Model 4). This change is not surprising; when neighbourhood descriptive variables are introduced, the differences in apartment prices are explained by location, as the neighbourhood effect is captured by the model and so is the neighbourhood variance.

In light of these results, we can conclude that Model $4 \mathrm{a}$ is very accurate. We obtain a pseudo$\mathrm{R}^{2}$ of 0.867 , a very satisfactory level if we compare it with that obtained in previous valuation studies (Fan et al. 2006; Selim 2009). No further neighbourhood related variables need be added to improve the valuation model because the improvement range is very low. Instead, efforts should be made to improve the description of the apartments and blocks.

When comparing HLM Model 4a and OLS Model 4b, we can see that they have similar residual variance and pseudo- $R^{2}$ and $R^{2}$ are very close, although pseudo- $\mathrm{R}^{2}$ is slightly better. This does not mean that the OLS model is as good as the HLM model. As Giuliano et al. (2010) pointed out, traditional OLS assumes that all observations are independent. In a real estate appraisal context OLS will yield biased and inefficient results, as it cannot take into account within-group correlations or interactions between residence and neighbourhood attributes and cannot distinguish between group effects and individual effects. The hierarchical structure of the HLM model can solve these problems. In fact, all estimated variances of the parameters in HLM are lower than those in OLS. Furthermore, HLM makes it possible to quantify the proportion of total variance that is explained by different levels.

Figure 2 shows neighbourhood effects, with $95 \%$ confidence intervals, for each of the four HLM models and it can be seen there are as many effects as postal codes. These effects represent postal code deviations from the average of overall log-price estimations, which will depend on the model applied. Therefore, a postal code whose confidence interval does not include zero is said to differ significantly from the overall log-price average at the $5 \%$ level. The postal codes on the right-hand side are those whose average estimated price is higher than the overall average and those whose average estimated price is below the 

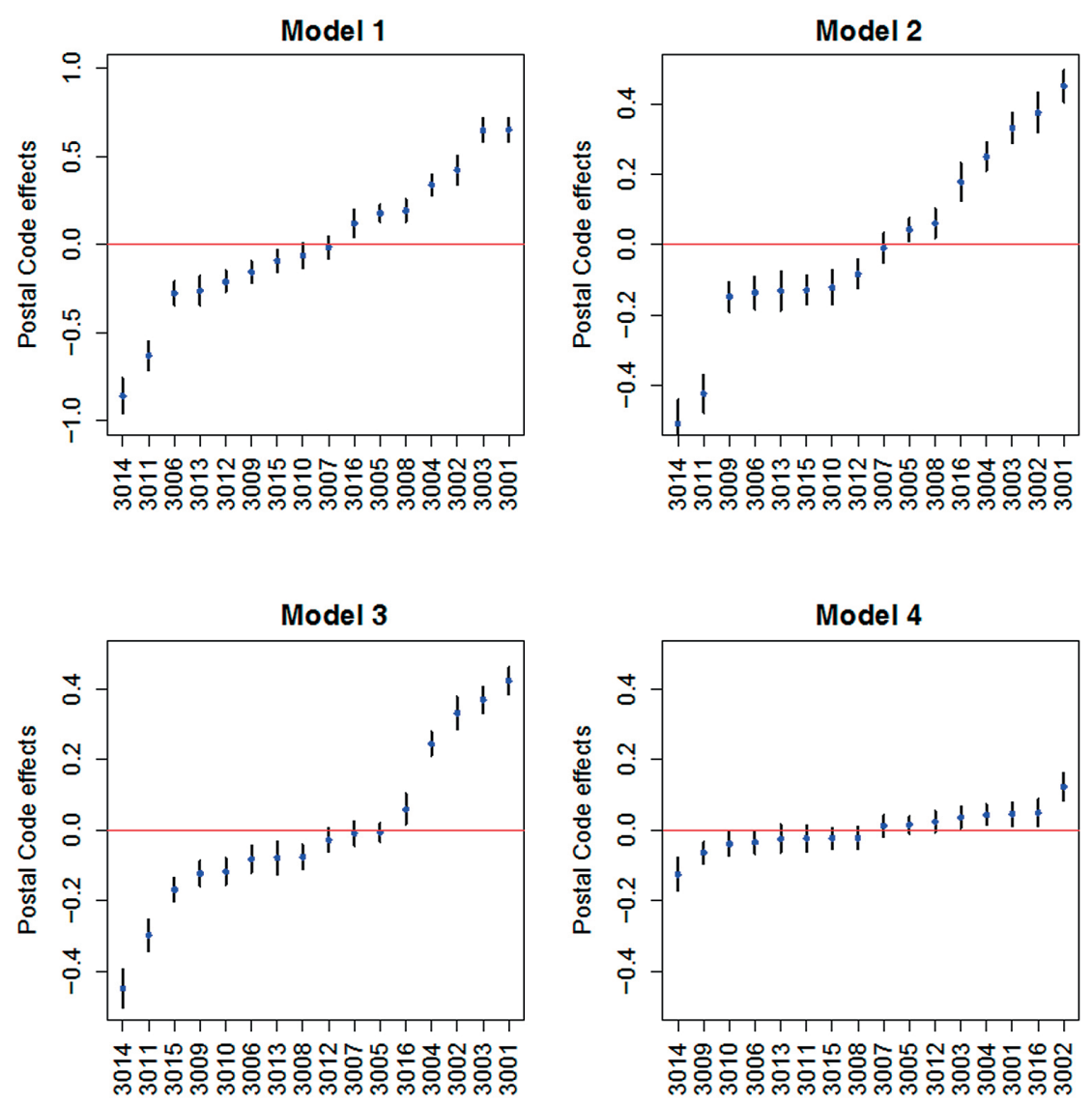

Fig. 2. Postal code-effects for each of the four HLM models, 95\% confidence intervals. Y-axis scale in Model 1 differs from the others

overall average are on the left. For example, in Model 2 (top-right panel in Figure 2), the average of the log-prices of the apartments in postal code 03001 are 0.45 higher than the overall estimated log-prices, i.e. $45 \%$ higher than the overall price predicted by Model 2. Meanwhile, apartments in postal code 03014 have an average estimated price $51 \%$ lower than the overall price predicted by Model 2. Finally, the average estimated price of the apartments in postal code 03007 does not differ from the overall price.

It can be observed that, as Model 1 only consists of the intercept, the deviations from the overall average are very high. An apartment in postal code 03011 or 03014 has a mean estimated price $50 \%$ or less than the mean global price of an apartment of the same characteristics. At the other end, an apartment in postal codes 03001 or 03003 has a mean estimated price more than 50\% higher than the global mean of an apartment of the same characteristics. When apartment descriptive variables are introduced in Model 2, deviations from the mean price are reduced to a large extent, but deviations continue to be prominent. Apartments that have a mean price substantially lower than the global mean price due to their location are still those in postal codes 03011 and 03014. On average, one of these apartments has a mean estimated price more than $40 \%$ lower than the mean global price of an apartment of the same characteristics. Apartments in the city centre (postal codes 03001 to 03004 ) are $20-45 \%$ more expensive than similar apartments in other neighbourhoods of Alicante. Apartments in sea-front postal code 03016 show a similar behaviour. These results do not change when block descriptive variables are introduced in Model 3. In this Model, the special behaviour of apartments in postal codes 03001 to 03004 becomes even more apparent.

Nevertheless, when neighbourhood related variables are included in Model 4a, the above-mentioned discrepancies almost disappear. In fact, in Model 4 an apartment in postal code 03002 has a mean estimated price only $12 \%$ higher than the mean apartment in Alicante with similar characteristics. 
The mean estimated price of the apartments in postal code 03014 is $13 \%$ lower. This means that when information on the neighborhood characteristics is included in the model, the postal code effect loses its relevance. However, the remaining postal code effect is still showing that there is a big difference between neighborhoods, which can generate price differences of up to $25 \%$ between the apartments in postal codes 03002 and 03014 . For the apartments in postal codes 03005, 03007, 03008, 03011, 03012, 03013 and 03015 all relevant information at the neighborhood level is included in the model, as their prices do not differ significantly from the overall estimated prices.

\section{CONCLUSIONS}

In this study, the hierarchical linear model (HLM) was applied to residential real estate mass appraisal. While multilevel models have already been used in many fields like education, sociology or politics, to the best of our knowledge this is the first time that this method has been applied to mass appraisal.

Compared to the traditional hedonic regression models, HLM explicitly considers that the price of the apartments in the same neighborhood is not independent, as it will be influenced by the characteristics of the neighborhood. In a real estate appraisal context, OLS will yield biased and inefficient results, as it cannot take into account within-group correlations or interactions between residence and neighborhood attributes.

Moreover, HLM gives valuable information on the percentage of the variance error caused by each level in the hierarchical model. In the present research, explicative variables were gathered into two groups or levels in order to determine which one best explains price variability: the first group included variables that describe the apartment and the block and the second included variables that describe the neighborhood.

The estimation of the model was made using a large database with information on 2,149 apartments in the city of Alicante, Spain, including 10 quantitative and 7 qualitative variables.

The results show a satisfactory goodness of fit with a pseudo $R^{2}$ of 0.867 for HLM, with all estimated variances of the parameters in HLM being lower than those in OLS.

HLM also identified some possible improvements regarding the information collected by the appraisers, as we detected that for 14 of the 16 neighborhoods the residual variance is concentrated at the apartment level, not at the neighborhood level. This means that, in order to enhance the goodness of fit of the model, it would not be efficient to collect more information on the neighborhood, but the effort should concentrate on the information describing the apartments.

\section{REFERENCES}

Aitkin, M.; Anderson, D.; Hinde, J. 1981. Statistical modelling of data on teaching styles, Journal of the Royal Statistical Society, Series A 144: 148-161. http://dx.doi.org/10.2307/2981826

Antipov, E. A.; Pokryshevskaya, E. B. 2012. Mass appraisal of residential apartments: an application of Random forest for valuation and CART-based approach for model diagnostics, Expert Systems with Applications 39: 1772-1778. http://dx.doi. org/10.1016/j.eswa.2011.08.077

Aznar, J.; Ferrís-Oñate, J.; Guijarro, F. 2010. An ANP framework for property pricing combining quantitative and qualitative attributes, Journal of the Operational Research Society 61(5): 740-755. http://dx.doi. org/10.1057/jors.2009.31

Aznar, J.; Guijarro, F.; Moreno-Jiménez, J. M. 2011. Mixed valuation methods: a combined AHP-GP procedure for individual and group multicriteria agricultural valuation, Annals of Operations Research 190(1): 221-238. http://dx.doi.org/10.1007/s10479009-0527-2

Basu, S.; Thibodeau, T. G. 1998. Analysis of spatial autocorrelation in house prices, Journal of Real Estate Finance and Economics 17(1): 61-85. http://dx.doi. org/10.1023/A:1007703229507

Brown, K. H.; Uyar, B. 2004. A hierarchical linear model approach for assessing the effects of house and neighborhood characteristics on housing prices, Journal of Real Estate Practice and Education 7(1): 15-23.

Cervelló, R.; García, F.; Guijarro, F. 2011. Ranking residential properties by a multicriteria single price model, Journal of the Operational Research Society 62: 1941-1950. http://dx.doi.org/10.1057/jors.2010.170

D'Amato, M. 2007. Comparing rough set theory with multiple regression analysis as automated valuation methodologies, International Real Estate Review 10(2): 42-65.

D'Amato, M. 2010. A location value response surface model for mass appraising: an "iterative" location adjustment factor in Bari, Italy, International Journal of Strategic Property Management 14(3): 231-244. http://dx.doi.org/10.3846/ijspm.2010.17

Downes, T. A.; Zabel, J. E. 2002. The impact of school characteristics on house prices: Chicago, Journal of Urban Economics 52: 1-25. http://dx.doi.org/10.1016/ S0094-1190(02)00010-4

Duncan, C.; Jones, K.; Moon, G. 1993. Do places matter? A multilevel analysis of regional variations in healthrelated behaviour in Britain, Social science and Medicine 37: 725-733. http://dx.doi.org/10.1016/02779536(93)90366-C 
Ecer, F. 2014. A hybrid banking websites quality evaluation model using AHP and COPRAS-G: a Turkey case, Technological and Economic Development of Economy 20(4): 758-782. http://dx.doi.org/10.3846/2 0294913.2014 .915596

Fagan, A. A.; Wright, E. M.; Pinchevsky, G. M. 2015. Exposure to violence, substance use, and neighborhood context, Social Science Research 49: 314-326. http:// dx.doi.org/10.1016/j.ssresearch.2014.08.015

Fan, G. Z.; Ong, S. E.; Koh, H. C. 2006. Determinants of house price: a decision tree approach, Urban Studies 43(12): 2301-2315. http://dx.doi. org/10.1080/00420980600990928

Farmer, M. C.; Lipscomb, C. A. 2010. Using quantile regression in hedonic analysis to reveal submarket competition, Journal of Real Estate Research 32(4): 435-460.

Ferreira, E.; Sirmans, G. 1988. Ridge regression in real estate analysis, The Appraisal Journal 56(3): 311-319.

García, N.; Gámes, M.; Alfaro, E. 2008. ANN + GIS: an automated system for property valuation, Neurocomputing 71: 733-742. http://dx.doi.org/10.1016/j.neucom.2007.07.031

Gelman, A.; Fagana, J.; Kiss, A. 2007. An analysis of the New York City Police Department's "stop-and-frisk" policy in the context of claims of racial bias, Journal of the American Statistical Association 102(479): 813823. http://dx.doi.org/10.1198/016214506000001040

Giuliano, G.; Gordon, P.; Pan, Q.; Park, J. Y. 2010. Accessibility and residential land values: Some tests with new measures, Urban Studies 47(14): 31033130. http://dx.doi.org/10.1177/0042098009359949

Gloudemans, R. J. 1999. Mass appraisal of real property. International Association of Assessing Officers.

Isakson, H. R. 2001. Using multiple regression in real estate appraisal, The Appraisal Journal 69(4): 424-430.

Kontrimas, V.; Verikas, A. 2011. The mass appraisal of real estate by computational intelligence, $A p$ plied Soft Computing 11: 443-448. http://dx.doi. org/10.1016/j.asoc.2009.12.003

Lee, C. C. 2009. Hierarchical linear modelling to explore the influence of satisfaction with public facilities on housing prices, International Real Estate Review 12(3): 252-272.

Mihi-Ramirez, A.; Metelski, D.; Rudžionis, A. 2013. The migration flow between Lithuania and Spain: a study of economic factors, Intellectual Economics 7(4): 426-438. http://dx.doi.org/10.13165/IE-13-7-4-02

Narula, S. C.; Wellington, J. F.; Lewis, S. A. 2012. Valuating residential real estate using parametric programming, European Journal of Operational Research 217: 120-128. http://dx.doi.org/10.1016/j. ejor.2011.08.014

Palmquist, R. B. 1984. Estimating the demand for the characteristics of housing, Review of Economics and Statistics 66: 394-404. http://dx.doi. org/10.2307/1924995
R Core Team. 2014. R: a language and environment for statistical computing. R Foundation for Statistical Computing. Vienna, Austria.

Raudenbush, S. W.; Bryk, A. S. 1986. A hierarchical model for studying school effects, Sociology of Education 59(1): 1-17. http://dx.doi.org/10.2307/2112482

Rudzkis, R.; Valkavičienè, R. 2014. Econometric models of the impact of macroeconomic processes on the stock market in the Baltic countries, Technological and Economic Development of Economy 20(4): 783800. http://dx.doi.org/10.3846/20294913.2014.949901

Štreimikienè, D. 2014. Housing indicators for assessing quality of life in Lithuania, Intellectual Economics 8(1): 25-41. http://dx.doi.org/10.13165/IE-14-8-1-02

Titko, J.; Stankevičienè, J.; Lāce, N. 2014. Measuring bank efficiency: DEA application, Technological and Economic Development of Economy 20(4): 739-757. http://dx.doi.org/10.3846/20294913.2014.984255

Raslanas, S.; Zavadskas, E. K.; Kaklauskas, A.; Zabulenas, A. R. 2010. Land value tax in the context of sustainable urban development and assessment. Part II - analysis of land valuation techniques: the case of Vilnius, International Journal of Strategic Property Management 14(2): 173-190. http://dx.doi. org/10.3846/ijspm.2010.13

Selim, H. 2009. Determinants of house prices in Turkey: hedonic regression versus artificial neural network, Expert Systems with Applications 36(2): 2843-2852. http://dx.doi.org/10.1016/j.eswa.2008.01.044

Singh, J. 2014. Effect of school and home factors on learning outcomes at elementary school level: a hierarchical linear model, Education 3-13 44(2): 116-139. http://dx.doi.org/10.1080/03004279.2014.899383

Snijders, T.; Bosker, R. 1999. Multilevel analysis: an introduction to basic and advanced multilevel modelling. London: Sage Publications.

Tanaka, H.; Uejima, S.; Asai, K. 1982. Linear regression analysis with fuzzy model, IEEE Transactions on Systems Man and Cybernetics 12(6): 903-907. http:// dx.doi.org/10.1109/TSMC.1982.4308925

Tay, D.; Ho, D. 1992. Artificial intelligence and the mass appraisal of residential apartments, Journal of Property Valuation and Investment 10(2): 525-540. http:// dx.doi.org/10.1108/14635789210031181

Tso, G. K.; Guan, J. 2014. A multilevel regression approach to understand effects of environment indicators and household features on residential energy consumption, Energy 66: 722-731. http://dx.doi. org/10.1016/j.energy.2014.01.056

Wang, W.; Rothschild, D.; Goel, S.; Gelman, A. 2015. Forecasting elections with non-representative polls, International Journal of Forecasting 31(3): 980-991. http://dx.doi.org/10.1016/j.ijforecast.2014.06.001 